\title{
Distinct roles of the endocannabinoids anandamide and 2-arachidonoylglycerol in social behavior and emotionality at different developmental ages in rats
}

\author{
Antonia Manduca ${ }^{a}$, Maria Morena ${ }^{\mathrm{b}, \mathrm{c}}$, Patrizia Campolongo ${ }^{\mathrm{b}}$, \\ Michela Servadio ${ }^{a}$, Maura Palmery ${ }^{b}$, Luigia Trabace ${ }^{d}$, \\ Matthew N. Hill ${ }^{c}$, Louk J.M.J. Vanderschuren ${ }^{e, f}$, \\ Vincenzo Cuomo ${ }^{b}$, Viviana Trezza ${ }^{a, *}$
}

\author{
${ }^{a}$ Department of Science, Section of Biomedical Sciences and Technologies, University "Roma Tre", Rome, \\ Italy \\ ${ }^{\mathrm{b}}$ Department of Physiology and Pharmacology, Sapienza, University of Rome, Rome, Italy \\ ${ }^{\mathrm{C}}$ Hotchkiss Brain Institute, Departments of Cell Biology and Anatomy and Psychiatry, University of Calgary, \\ Calgary, $A B$, Canada \\ ${ }^{\mathrm{d}}$ Department of Clinical and Experimental Medicine, Faculty of Medicine, University of Foggia, Foggia, \\ Italy \\ eDepartment of Translational Neuroscience, Brain Center Rudolf Magnus, University Medical Center \\ Utrecht, Utrecht, The Netherlands \\ ${ }^{\mathrm{f}}$ Department of Animals in Science and Society, Division of Behavioural Neuroscience, Faculty of Veterinary \\ Medicine, Utrecht University, Utrecht, The Netherlands
}

Received 30 November 2014; received in revised form 25 February 2015; accepted 1 April 2015

KEYWORDS

Endocannabinoid sys-

tem;

Social behavior;

Endocannabinoids;

Emotional behavior;

Rodents;

JZL195

\begin{abstract}
To date, our understanding of the relative contribution and potential overlapping roles of the endocannabinoids anandamide (AEA) and 2-arachidonoylglycerol (2-AG) in the regulation of brain function and behavior is still limited. To address this issue, we investigated the effects of systemic administration of JZL195, that simultaneously increases AEA and 2-AG signaling by inhibiting their hydrolysis, in the regulation of socio-emotional behavior in adolescent and adult rats.

JZL195, administered at the dose of $0.01 \mathrm{mg} / \mathrm{kg}$, increased social play behavior, that is the most characteristic social activity displayed by adolescent rats, and increased social interaction in adult animals. At both ages, these behavioral effects were antagonized by the CB1 cannabinoid receptor antagonist SR141716A and were associated with increased brain levels of 2-AG, but not
\end{abstract}

\footnotetext{
*Corresponding author. Tel.: +39 0657336343; fax: + 390657336365.
}

E-mail address: viviana.trezza@uniroma3.it (V. Trezza). 
AEA. Conversely, at the dose of $1 \mathrm{mg} / \mathrm{kg}$, JZL195 decreased general social exploration in adolescent rats without affecting social play behavior, and induced anxiogenic-like effects in the elevated plus-maze test both in adolescent and adult animals. These effects, mediated by activation of CB1 cannabinoid receptors, were paralleled by simultaneous increase in AEA and 2-AG levels in adolescent rats, and by an increase of only 2-AG levels in adult animals.

These findings provide the first evidence for a role of 2-AG in social behavior, highlight the different contributions of $\mathrm{AEA}$ and $2-\mathrm{AG}$ in the modulation of emotionality at different developmental ages and suggest that pharmacological inhibition of AEA and 2-AG hydrolysis is a useful approach to investigate the role of these endocannabinoids in neurobehavioral processes.

(c) 2015 Elsevier B.V. and ECNP. All rights reserved.

\section{Introduction}

In recent years, the endocannabinoid system has emerged as a key neuromodulatory system in the regulation of emotional states, that is functional already at early developmental ages (Bari et al., 2006; Campolongo et al., 2011; Lutz, 2009; Marco and Laviola, 2011; Morena and Campolongo, 2014; Trezza et al., 2012a; Wotjak, 2005). The most studied endocannabinoids, $\mathrm{N}$-arachidonoylethanolamine (anandamide, AEA) and 2-arachidonoylglycerol (2-AG) are lipid signaling molecules implicated in a large range of neurobiological processes. They are synthesized following neuronal depolarization (Mechoulam et al., 2014; Piomelli, 2003); once released from postsynaptic neurons, they exert their effects through the activation of at least two presynaptic G-protein coupled cannabinoid receptors (CB1 and CB2). Finally, their actions are terminated by a putative uptake process followed by degradation by fatty acid amide hydrolase (FAAH) and monoacylglycerol lipase (MAGL), hydrolytic enzymes that provide the primary clearance routes for AEA and 2-AG (Mechoulam et al., 2014; Piomelli, 2003).

To clarify the physiological role of endocannabinoids in neurobehavioral functions, a number of pharmacological tools have been developed, which target the enzymes involved in endocannabinoid degradation. This pharmacological approach has the advantage of increasing local endocannabinoid neurotransmission, instead of indiscriminately activating brain CB1 cannabinoid receptors using direct CB1 cannabinoid agonists (Bari et al., 2006; Petrosino and Di Marzo, 2010). Selective pharmacological inhibition of FAAH in rodents contributed to elucidate the role of AEA in socioemotional processes. Thus, FAAH inhibition results in CB1mediated and context-dependent anxiolytic- and antidepressant-like effects in rats and mice (Gobbi et al., 2005; Hill et al., 2007; Kathuria et al., 2003; Naidu et al., 2007; Rademacher and Hillard, 2007; Realini et al., 2011), and increased sociability in adolescent (Trezza et al., 2012b; Trezza and Vanderschuren, 2008a, 2008b) and adult rats (Manduca et al., 2014; Realini et al., 2011).

More recently, the development of selective MAGL inhibitors (Chang et al., 2012; Long et al., 2009a; Niphakis et al., 2013) has enabled the direct investigation of the role of 2-AG in physiological and behavioral processes. It has been reported that selective inhibition of 2-AG hydrolysis induces CB1-dependent anxiolytic-like effects in rodents
(Kinsey et al., 2011; Sciolino et al., 2011) and normalizes both synaptic and behavioral changes observed in the mouse model of the Fragile X syndrome (Jung et al., 2012), opening a promising therapeutic potential for these compounds in the treatment of neurodevelopmental disorders.

Altogether, these studies show that the development of selective inhibitors for either FAAH or MAGL has facilitated the comprehension of the (patho) physiological role of AEA and 2-AG signaling pathways, respectively. Interestingly, the previously unexpected discovery of functional interactions between these two endocannabinoids has led to the hypothesis that AEA and 2-AG do not always have the same physiological role, acting sometimes in concert and sometimes not (Di Marzo and Cristino, 2008; Maccarrone et al., 2008).

In the present study, we investigated the relative contribution, and potential overlapping roles, of AEA and 2-AG in socioemotional processes in rats. To this aim, we tested the dual FAAH/MAGL inhibitor JZL195, that simultaneously inhibits both AEA and 2-AG catabolic enzymes (Long et al., 2009b), in the social interaction and elevated plus-maze tests, two tasks sensitive to environmental and physiological factors that affect emotionality in rodents. Since temporal changes in endocannabinoid brain content and metabolism have been reported in rodents (Lee et al., 2013; Rubino et al., 2014), the effects of the drug were assessed in adolescent and adult rats. Furthermore, since it has been shown that JZL195 induces a characteristic profile of dose-dependent cannabimimetic effects in mice (Long et al., 2009b), we also screened JZL195-treated rats in the tetrad test currently used to assess cannabimimetic activity in vivo (Compton et al., 1992). Last, we explored the possible underpinnings of the observed behavioral findings by measuring brain AEA and 2-AG levels in adolescent and adult JZL195-treated rats.

\section{Experimental procedures}

\section{Animals}

Male Sprague-Dawley rats (Charles River Laboratories, Italy) arrived in our animal facility at 21 days of age and were housed in groups of five in Macrolon cages $\left(43 \times 26 \times 20 \mathrm{~cm}^{3}\right)$ under controlled conditions (i.e., temperature $21 \pm 1{ }^{\circ} \mathrm{C}, 60 \pm 10 \%$ relative humidity and $12 / 12 \mathrm{~h}$ light cycle with lights on at $7.00 \mathrm{a} . \mathrm{m}$.). Food and water were available ad libitum. Animals were experimentally naïve and used only once (i.e., each animal received one injection only, with either drug or vehicle, 
and tested in one behavioral experiment only). All procedures were approved by the Italian Ministry of Health (Rome, Italy) and performed in agreement with the guidelines of the Italian Ministry of Health (D.L. 26/2014) and the European Community Directive 2010/63/EU of 22 September 2010.

\section{Drugs}

The dual FAAH/MAGL inhibitor JZL195 (Schering-Plough Research Institute, Newhouse, UK) and the CB1 cannabinoid receptor antagonist SR141716A (National Institute of Mental Health's Chemical Synthesis and Drug Supply Program, Bethesda, MD, USA) were dissolved in 5\% Tween $80 / 5 \%$ polyethylene glycol/saline and given intraperitoneally (i.p.).

JZL195 $(0.01,0.1$ and $1 \mathrm{mg} / \mathrm{kg})$ or its vehicle was administered $2 \mathrm{~h}$ before testing; SR141716A was administered $30 \mathrm{~min}$ before JZL195, at a dose that did not induce effects by itself $(0.1 \mathrm{mg} / \mathrm{kg}$ in adolescent rats (Trezza and Vanderschuren, 2008b) and $1 \mathrm{mg} / \mathrm{kg}$ in adult rats (Gobbi et al., 2005; Sciolino et al., 2011). Drug doses and pre-treatment intervals were based on the literature (Long et al., 2009b; Trezza and Vanderschuren, 2008b) and on pilot experiments. Solutions were freshly prepared on the day of the experiment and were administered in a volume of $2 \mathrm{ml} / \mathrm{kg}$ in adolescent rats and $1 \mathrm{ml} / \mathrm{kg}$ in adult rats.

\section{Apparatus and procedure}

\section{Social behavior in adolescent and adult rats}

The experiments were performed in a sound attenuated chamber under dim light conditions between $10.00 \mathrm{am}$ and $14.00 \mathrm{am}$. The testing arena consisted of a Plexiglas cage measuring $40 \times 40 \times 60$ $\mathrm{cm}^{3}(l \times w \times h)$, with $2 \mathrm{~cm}$ of wood shavings covering the floor. The behavior of the animals was recorded using a video camera with zoom lens, DVD recorder and LCD monitor.

Social behavior was assessed as previously described (Manduca et al., 2014; Trezza and Vanderschuren, 2008a, 2008b, 2009; Vanderschuren et al., 2008).

Briefly, adolescent (28-35 day-old) or adult (80-90 day-old) rats were individually habituated to the test cage for either 10 (adolescent rats) or $5 \mathrm{~min}$ (adult rats) on each of the 2 days prior to testing. Before testing, adolescent and adult animals were socially isolated for 3.5 and $24 \mathrm{~h}$, respectively, to enhance their social motivation and thus facilitate the expression of social behaviors during testing (Niesink and Van Ree, 1989). Drug treatments were counterbalanced so that cage mates were allocated to different treatment groups. The animals of each pair were similarly treated, did not differ more than $10 \mathrm{~g}$ in body weight and were not cage mates.

Behavior was assessed per pair of animals and analyzed by a trained observer who was unaware of treatment condition using the Observer XT software (Noldus, Wageningen, The Netherlands).

The test consisted of placing two similarly treated animals into the test cage for either $15 \mathrm{~min}$ (adolescent rats) or $10 \mathrm{~min}$ (adult rats). In rats, a bout of social play behavior starts with one rat soliciting ('pouncing') another animal, by attempting to nose or rub the nape of its neck. The animal that is pounced upon can respond in different ways. If the animal that is pounced upon fully rotates to its dorsal surface, 'pinning' is the result, i.e., one animal lying with its dorsal surface on the floor with the other animal standing over it. From this position, the supine animal can initiate another play bout, by trying to gain access to the other animal's neck. Thus, during social play, pouncing is considered an index of play solicitation, while pinning can be regarded as the terminal component of a single play bout as well as a releaser of a prolonged play bout (Pellis and Pellis, 1987). Pinning and pouncing frequencies can be easily quantified and they are considered to be the most characteristic parameters of social play behavior in rats. During the social encounter, animals may also display social behaviors not directly associated with play, such as sniffing or grooming the partner's body.

A pair of rats was considered as one experimental unit.

In adolescent rats, the following parameters were therefore scored per pair of animals:

Social behaviors directly related to play:

- Frequency of pinning.

- Frequency of pouncing.

Social behaviors unrelated to play:

- Time spent in social exploration: the total amount of time (s) spent in non-playful forms of social interaction (i.e., one animal sniffing or grooming any part of the partner's body).

In adult rats, the total time and total frequency of active social interactions were obtained as the sum of the time and frequency of the following behavioral elements scored per $10 \mathrm{~min}$ (Manduca et al., 2014; Segatto et al., 2014):

- Play-related behaviors: pouncing, pinning and boxing.

- Social behaviors unrelated to play: social exploration (sniffing any part of the body of the test partner), social grooming (one rat licks and chews the fur of the conspecific, while placing its forepaws on the back or the neck of the other rat), following/ chasing (walking or running in the direction of the partner which stays where it is or moves away), crawling under/over (one animal crawls underneath or over the partner's body, crossing it transversely from one side to the other), kicking (the rat kicks backwards at the conspecific with one or both hind paws).

\section{Elevated plus-maze test in adolescent and adult rats}

The elevated plus-maze apparatus comprised two open arms $\left(50 \times 10 \times 40 \mathrm{~cm}^{3} ; l \times w \times h\right)$ and two closed arms $\left(50 \times 10 \times 40 \mathrm{~cm}^{3}\right.$; $l \times w \times h)$ that extended from a common central platform $\left(10 \times 10 \mathrm{~cm}^{2}\right)$. The test was performed as previously described (Pellow and File, 1986; Segatto et al., 2014; Trezza et al., 2009). Adolescent (28-35 days of age) and adult (80-90 days of age) rats were individually placed on the central platform of the maze, facing a closed arm, and allowed to freely explore the maze for $5 \mathrm{~min}$.

The 5-min test period was recorded on DVD for subsequent behavioral analysis carried out an observer, unaware of animal treatment, using the Observer 3.0 software (Noldus Information Technology B.V., Wageningen, The Netherlands).

The following parameters were analyzed:

a. \% time spent in the open arms (\% TO): (seconds spent on the open arms of the maze/seconds spent on the open+closed arms) $\times 100$;

b. \% open arm entries (\% $\mathrm{OE})$ : (the number of entries into the open arms of the maze/number of entries into open +closed arms) $\times$ 100 ;

c. number of closed arm entries.

\section{Tetrad assay for cannabimimetic activity}

To assess whether the effects of the dual FAAH/MAGL inhibitor JZL195 in the social behavior and elevated plus-maze tests were behaviorally specific and not secondary to more general CB1-mediated behavioral responses, we screened JZL195-treated rats in the tetrad test currently 
used to assess cannabimimetic activity in vivo, consisting of assays for antinociception, catalepsy, hypomotility, and hypothermia (Compton et al., 1992; Long et al., 2009b).

At 28-35 days of age, rats were injected with either vehicle or JZL195 $(0.01,0.1$ and $1 \mathrm{mg} / \mathrm{kg}) 2 \mathrm{~h}$ before testing and the tetrad assay was performed in the same animal in the following order: measurements of body temperature, locomotor activity, catalepsy and nociceptive behavior. Body temperature was measured using a rectal probe (Physitemp Instruments, Clifton, $\mathrm{NJ}$ ) and was expressed as the change in body temperature from the pre-drug baseline $\left(\Delta^{\circ} \mathrm{C}\right)$. Locomotor activity was recorded using the software SMART Video Track System (PanLab, Spain) during a 30-min test in which rats were placed alone in the center of the open field (a black Plexiglas cage $\left(80 \times 80 \times 60 \mathrm{~cm}^{3}\right)$ located within a sound-isolated room under dim light conditions) and allowed to explore freely the apparatus. A video camera above the cage was connected to a video recorder and locomotor activity (the total distance moved in $\mathrm{cm}$ during the 30 -min test session) and exploratory behaviors (the total frequency of wall rearings and rearings) were evaluated.

Subsequently, the same animal was individually tested for catalepsy by placement of both forelimbs over a thin metal bar $(0.75 \mathrm{~cm}$ diameter) fixed at $10 \mathrm{~cm}$ above the ground. Animals were timed for the latency to move one or both forelimbs from the bar, with the maximum time allowed on the bar being $30 \mathrm{~s}$ (Long et al., 2009b).

Last, nociception was assessed using the hot-plate procedure described by Forman (Forman, 2003). Rats were placed individually on a hot-plate (Socrel, model DS-37, Ugo Basile, Comerio, Italy) maintained at $52 \pm 1{ }^{\circ} \mathrm{C}$ and the latency to exhibit the first signs of pain (i.e., licking the hind paws or jumping) was measured for each rat with a cut-off of $30 \mathrm{~s}$. All the experiments were performed between $10.00 \mathrm{am}$ and $14.00 \mathrm{am}$.

\section{Endocannabinoid extraction and analysis}

Brain AEA and 2-AG levels were measured in separate groups of adolescent and adult rats $2 \mathrm{~h}$ after JZL195 $(0.01,0.1$ and $1 \mathrm{mg} / \mathrm{kg})$ or vehicle injection. After rapid decapitation, the brains were collected and stored at $-80^{\circ} \mathrm{C}$. Before the extraction process, the brain tissue was weighed and placed into borosilicate glass culture tubes containing $2 \mathrm{ml}$ of acetonitrile $(\mathrm{ACN})$ with $5 \mathrm{pmol}$ of $\left[{ }^{2} \mathrm{H}_{8}\right]$ anandamide and $5 \mathrm{nmol}$ of $\left[{ }^{2} \mathrm{H}_{8}\right] 2$-arachidonoylglycerol for extraction, and homogenized with a glass rod. Tissue was sonicated for $30 \mathrm{~min}$ on ice water and incubated overnight at $-20{ }^{\circ} \mathrm{C}$ to precipitate proteins, then centrifuged at $1500 \mathrm{~g}$ to remove particulates. The supernatants were transferred to a new glass tube and evaporated to dryness under $\mathrm{N}_{2}$ gas. The samples were reconstituted in $300 \mu \mathrm{l}$ of ACN and dried again under $\mathrm{N}_{2}$ gas. Finally, lipid extracts were suspended in $200 \mu \mathrm{l}$ of $\mathrm{ACN}$, and stored at $-80^{\circ} \mathrm{C}$ until analysis. Liquid chromatography-mass spectrometry (LC-MS/ MS) analyses were carried out on an Eksigent ekspert ${ }^{\mathrm{TM}}$ micro LC 200 coupled with an AB Sciex Qtrap ${ }^{\mathrm{TM}} 5500$ mass spectrometer, installed with a Turbo VTM Spray ion source (AB Sciex, Ontario, Canada). The LC was equipped with a temperature-controlled CTC autosampler. An Eksigent HALO C18 HPLC column $\left(1 \times 50 \mathrm{~mm}^{2}\right.$, $2.7 \mu \mathrm{m}$ particle diameter, $90 \AA$ pore size) was used. Samples were analyzed isocratically, at a flow rate of $30 \mu \mathrm{L} / \mathrm{min}$ and a solvent composition of $15 \%$ mobile phase A $(10 \mathrm{mM}$ ammonium acetate in water), and $85 \%$ mobile phase B (ACN). After $3.25 \mathrm{~min}$, the column was regenerated with $100 \% \mathrm{~B}$. Before each injection, the column was re-equilibrated at the initial mobile phase condition for $2 \mathrm{~min}$. Following each LC-MS/MS run, a blank was run. The sample injection loop ( $5 \mu \mathrm{L}$ loop size) was rinsed with $40 \mu \mathrm{L}$ of methanol, and the column purged for $5 \mathrm{~min}$ with $100 \%$ B for $4.5 \mathrm{~min}$ and followed by $85 \%$ B for $0.5 \mathrm{~min}$. This was intended to mitigate cross contaminations due to carryover from preceding sample injections. The $\mathrm{LC}$ column was maintained at $25^{\circ} \mathrm{C}$, and the samples at $10^{\circ} \mathrm{C}$. The mass spectrometer was operated in positive ion mode, with the ion-spray voltage set at $5500 \mathrm{~V}$, curtain gas at 20 (arbitrary units), source gas 1 and gas 2 both at 40, and source temperature at $300{ }^{\circ} \mathrm{C}$. Protonated molecular ions of AEA (m/z 348) and AEA-d8 (m/ z 356), and ammonium adduct ions of 2-AG (m/z 396) and 2-AG-d8, $(\mathrm{m} / \mathrm{z} 404)$ were selected as the respective precursor ions for CID. MRM scan modes were used with Q1 and Q3 both at unit resolution. Optimized collision energies for the transitions were as follows: AEA (348-62) CE 22V, AEA-d8 (356-62) CE 22V, 2-AG (396-287) CE 15V; and 2-AG-d8 (404-294) CE 17V. It has been reported that 2-AG undergoes spontaneous isomerization converting to 1-AG by acyl group migration during tissue extraction and reconstitution procedures (Stella et al., 1997). We also observed that 1-AG was present in authentic standard solutions of 2-AG, as well as brain tissue extracts. Peak areas of 1-AG and 2-AG were combined to establish a standard calibration curve for 2-AG. Data processing was accomplished using Analyst $\AA$ 1.5.2 software (AB Sciex). Linear regressions of relative peak areas (analyte to IS ratios) were performed over analyte concentrations from 0.00025 to $0.25 \mathrm{pmol} / \mu \mathrm{L}$ (AEA), and 0.0025 to $2.5 \mathrm{pmol} / \mu \mathrm{L}(2-\mathrm{AG})$. Analyte levels were normalized to tissue weight.

\section{Statistical analysis}

Data are expressed as mean \pm SEM. To assess the effects of single or combined treatments on the behavioral parameters and on brain AEA and 2-AG levels, data were analyzed using one- or two-way ANOVA. ANOVAs were followed by Student-Newman-Keuls post-hoc test, where appropriate. $P$ values of less than 0.05 were considered statistically significant.

\section{Results}

\section{Effects of JZL195 on social behavior in adolescent rats}

A one-way ANOVA analysis performed on pinning and pouncing frequencies and on the duration of social exploration gave the following results: pinning $\left[F_{3,39}=7.01 ; p=0.0007\right.$; Figure 1a]; pouncing $\left[F_{3,39}=4.05 ; p=0.013\right.$; Figure $\left.1 \mathrm{~b}\right]$; social exploration $\left[F_{3,39}=3.84 ; p=0.017\right.$; Figure $\left.1 c\right]$. Posthoc analysis revealed that JZL195 had biphasic effects on social behavior in adolescent rats: at the dose of $0.01 \mathrm{mg} /$ $\mathrm{kg}$, it increased play-associated behaviors (pinning: $p<0.01$, Figure 1a; pouncing: $p<0.05$, Figure $1 b$ ) without affecting general social exploration. Conversely, at the dose of $1 \mathrm{mg} /$ $\mathrm{kg}$, JZL195 reduced social exploration $(p<0.05$, Figure $1 \mathrm{c})$, with no effect on social play behavior.

To evaluate if these effects were mediated by activation of CB1 cannabinoid receptors, an additional group of adolescent rats was treated with the CB1 cannabinoid receptor antagonist SR141716A 30 min before administration of JZL195. A two-way ANOVA analysis performed on the behavioral parameters measured gave the following results: pinning $\left[F_{(J Z L 195)}\right.$ ${ }_{1,31}=2.46, \quad p=0.13 ; \quad F_{(\mathrm{SR}) 1,31}=5.71, \quad p=0.023 ; \quad F_{(\mathrm{JZL} 195 \times \mathrm{SR})}$ $1,31=4.50, \quad p=0.042 ;$ Figure $1 \mathrm{~d}]$; pouncing $\left[F_{(J Z L 195)}\right.$ $1,31=1.42, p=0.24 ; F_{(\mathrm{SR}) 1,31}=13.82, p=0.0008 ; F_{(\mathrm{JZL} 195 \times \mathrm{SR})}$ $1,31=6.99, p=0.013$; Figure 1e]; social exploration duration $\left[F_{(J Z L 195) 1,31}=1.62, \quad p=0.21 ; \quad F_{(\mathrm{SR}) 1,31}=1.09, \quad p=0.30 ;\right.$ $F_{(J Z L 195 \times \text { SR)1,31 }}=4.82, p=0.036$; Figure 1f]. Post-hoc analysis revealed that the increase in pinning $(p<0.05$, Figure $1 d)$ and pouncing $(p<0.01$, Figure 1 e) induced by JZL195 at the dose of $0.01 \mathrm{mg} / \mathrm{kg}$ was antagonized by pre-treatment with a dose of the CB1 cannabinoid receptor antagonist SR141716A that had no effects by its own $(0.1 \mathrm{mg} / \mathrm{kg})$. Similarly, 
a

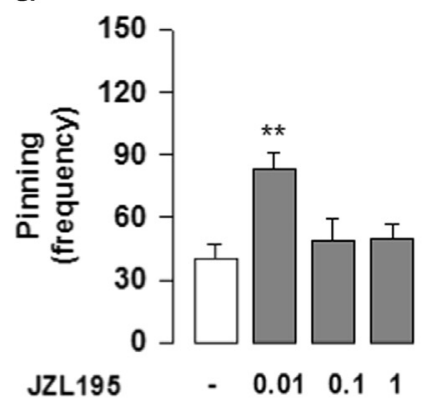

d

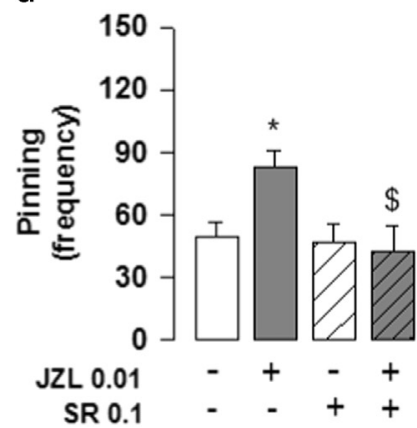

b

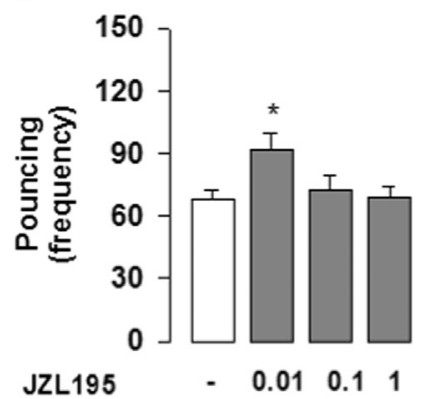

e

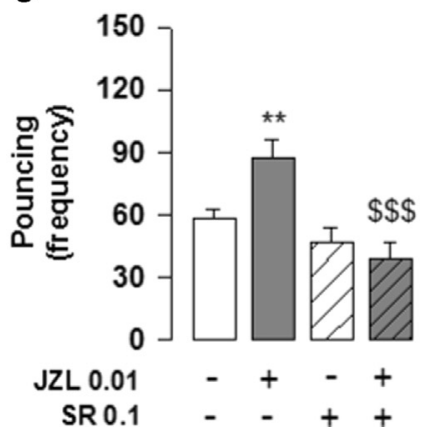

C

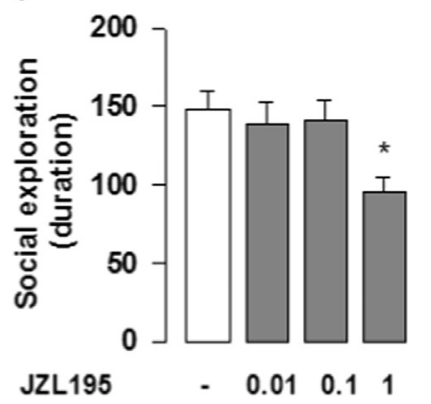

f

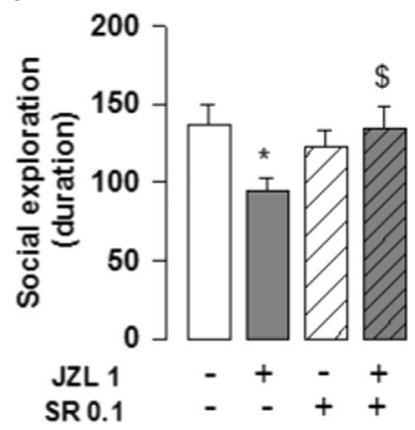

Figure 1 Effects of JZL195 on social play behavior in adolescent rats. At the dose of $0.01 \mathrm{mg} / \mathrm{kg}$, JZL195 increased pinning (a) and pouncing (b) frequency in adolescent rats, whereas at the dose of $1 \mathrm{mg} / \mathrm{kg}$ it decreased the duration of social exploration (c). Pretreatment with the CB1 cannabinoid receptor antagonist SR141716A $(0.1 \mathrm{mg} / \mathrm{kg}, i . p$. $)$ antagonized the effects induced by JZL195 on pinning (d) and pouncing (e) and social exploration (f). Data represent mean \pm SEM frequency of pinning (a, d), pouncing (b, e) and mean \pm SEM duration of social exploration (c, f). ${ }^{*} p<0.05,{ }^{*} p<0.01$ vs. vehicle treatment; ${ }^{\$} p<0.05,{ }^{\$ \$ \$} p<0.001$ vs. vehicle/JZL195 (Student-Newman-Keuls post-hoc test). $N=7-12$ per treatment group.

the reduction in the time spent in social exploration induced by $1 \mathrm{mg} / \mathrm{kg}$ of JZL195 ( $p<0.05$, Figure 1f) was antagonized by pre-treatment with SR141716A.

Altogether, these data indicate that JZL195 induces biphasic effects on social behavior in adolescent rats through activation of CB1 cannabinoid receptors.

\section{Effects of JZL195 on the elevated plus-maze test in adolescent rats}

A one-way ANOVA analysis performed on the parameters measured in the elevated plus-maze test gave the following results: percentage of time spent in the open arms $\left[F_{3,26}=6.29 ; p=0.002\right.$; Figure $\left.2 \mathrm{a}\right]$ and percentage of open arm entries $\left[F_{3,26}=5.84 ; p=0.0034\right.$; Figure $\left.2 b\right]$. Post-hoc analysis showed that, at the dose of $1 \mathrm{mg} / \mathrm{kg}$, JZL195 exerted anxiogenic-like effects in the elevated plus-maze test in adolescent rats, since it decreased the percentage of time spent in the open arms $(p<0.01$, Figure $2 a)$ and the percentage of open arm entries $(p<0.05$, Figure $2 b)$. These effects were not due to changes in motor activity, since JZL195 did not affect the total number of entries in the closed arms during the 5 -min test $\left[F_{3,26}=1.37 ; p=0.2\right.$, data not shown]. To evaluate if the anxiogenic-like effects exerted by JZL195 $(1 \mathrm{mg} / \mathrm{kg})$ were mediated by activation of CB1 cannabinoid receptors, we pre-treated the animals with the CB1 cannabinoid receptor antagonist SR141716A. Two-way ANOVA analysis gave the following results: percentage of time spent in the open arms $\left[F_{(J Z L 195) 1,32}=0.20\right.$, $\left.p=0.65 ; F_{(\mathrm{SR}) 1,32}=0.06, p=0.81 ; F_{(\mathrm{JZL} 195} \times \mathrm{SR}\right) 1,32=14.07$, $p=0.0007$; Figure $2 c]$ and percentage of open arm entries $\left[F_{(\mathrm{JZL} 195) 1,32}=1.11, \quad p=0.30 ; \quad F_{(\mathrm{SR}) 1,32}=1.59, \quad p=0.21 ;\right.$ $F_{(\mathrm{JZL} 195 \times \mathrm{SR}) 1,32}=7.77, p=0.0089$; Figure $\left.2 \mathrm{~d}\right]$. Post-hoc analysis showed that the reduction in the percentage of time spent in the open arms $(p<0.05$, Figure $2 c)$ and the percentage of open arm entries $(p<0.05$, Figure $2 d)$ induced by JZL195 $1 \mathrm{mg} / \mathrm{kg}$ was mediated by activation of CB1 cannabinoid receptors, since it was antagonized by pretreatment with an otherwise ineffective dose of the CB1 cannabinoid receptor antagonist SR141716A.

\section{Effects of JZL195 in the tetrad assay for cannabimimetic activity}

JZL195 did not affect locomotor activity and exploratory behaviors in the open field test (one-way ANOVA: total distance traveled $\left[F_{3,24}=1.49, p=0.24\right.$; Figure $\left.3 a\right]$, frequency of wall rearing $\left[F_{3,24}=1.07, p=0.38\right.$; Figure $\left.3 \mathrm{~b}\right]$ and frequency of rearing $\left[F_{3,24}=0.8, p=0.5\right.$; Figure $\left.3 c\right]$. Furthermore, JZL195-treated animals did not show changes in body temperature [ $F_{3,24}=0.18, p=0.91$; Figure $3 \mathrm{~d}$ ], neither catalepsy in the bar test (latency of the animals to move one or both forelimbs from the bar: $\left[F_{3,24}=2.38\right.$, $p=0.095$; Figure 3e]) nor antinociceptive response in the hot plate test $\left[F_{3,24}=1.74, p=0.18\right.$; Figure $\left.3 \mathrm{f}\right]$. Together, these data show that, at doses that affected social and anxiety-like behaviors, JZL195 did not induce classic cannabimimetic effects, since it did not alter locomotor and 

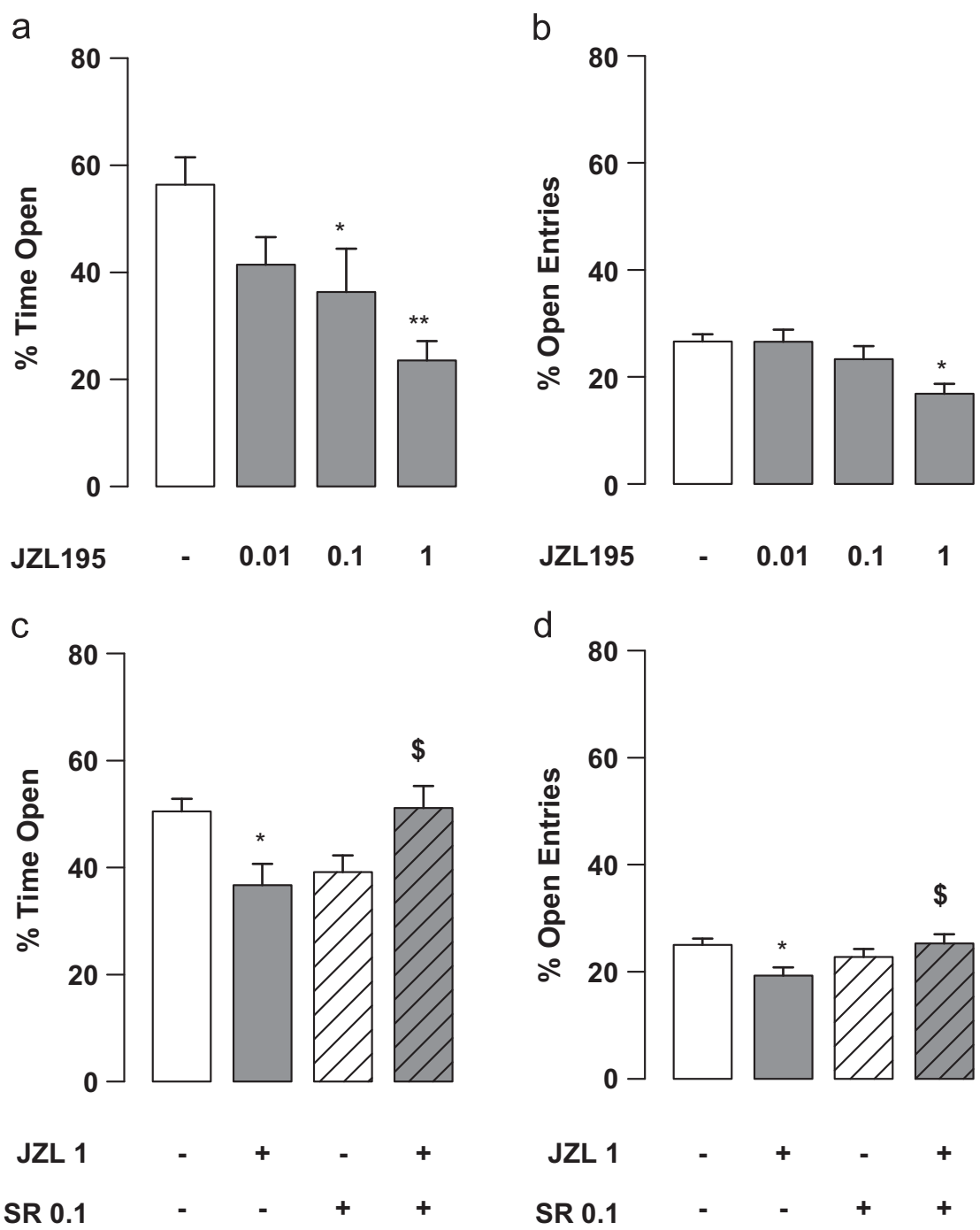

Figure 2 Effects of JZL195 in the elevated plus-maze test in adolescent rats. At the dose of $1 \mathrm{mg} / \mathrm{kg}$, JZL195 decreased the percentage of total time spent in the open arms (a) and the percentage of open arm entries (b) in the elevated plus-maze test in adolescent rats. Pre-treatment with the CB1 cannabinoid receptor antagonist SR141716A (0.1 mg/kg; i.p.) antagonized these effects (c, d). Data represent mean \pm SEM percentage of total time spent in open arms $(a, c)$ and open arm entries (b, d). ${ }^{*} p<0.05$, ${ }^{* *} p<0.01$ vs. vehicle treatment; ${ }^{\$} p<0.05$ vs. vehicle/JZL195 (Student-Newman-Keuls post-hoc test). $N=8-16$ per treatment group.

exploratory activity in the open field test and did not induce hypothermia, catalepsy and antinociception in rats.

\section{Effects of JZL195 on social interaction in adult rats}

A one-way ANOVA analysis performed on the parameters measured in the social interaction test in adult rats gave the following results: total time spent in social interaction: $\left[F_{3,38}=3.82 ; p=0.017\right.$; Figure $\left.4 \mathrm{a}\right]$, total frequency of social interaction $\left[F_{3,38}=5.61 ; p=0.0028\right.$; Figure $\left.4 b\right]$, total time spent in play-related behaviors $\left[F_{3,38}=3.09 ; p=0.038\right.$; Figure 4c], and total frequency of play-related behaviors $\left[F_{3,38}=3.54 ; \quad p=0.023 ;\right.$ Figure 4d]. Post-hoc analysis revealed that JZL195, at the dose of $0.01 \mathrm{mg} / \mathrm{kg}$, increased the total time $(p<0.05$, Figure $4 \mathrm{a})$ and frequency $(p<0.05$, Figure $4 \mathrm{~b}$ ) of social interaction. Furthermore, this dose of JZL195 increased the total time $(p<0.05$, Figure $4 c)$ and frequency $(p<0.05$, Figure $4 d$ ) of play-related behaviors. To evaluate, if these effects were mediated by activation of CB1 cannabinoid receptors, we injected the CB1 cannabinoid receptor antagonist SR141716A before JZL195. Twoway ANOVA analysis gave the following results: total time spent in social interaction: $\left[F_{(J Z L 195) 1,31}=4.25, p=0.48 ; F_{(S R)}\right.$ $\left.1,31=6.967, \quad p=0.013 ; \quad F_{(J Z L 195 \times} \times \mathrm{SR}\right) 1,31=1.64, \quad p=0.21$; Figure 4e], total frequency of social interaction [ $F_{(J Z L 195)}$ $\left.1,31=12.99, p=0.0011 ; F_{(\mathrm{SR}) 1,31}=1.54, p=0.22 ; F_{(\mathrm{JZL} 195} \times \mathrm{SR}\right)$ $1,31=4.13, p=0.05$; Figure $4 \mathrm{f}]$, total time spent in playrelated behaviors $\left[F_{(\mathrm{JZL195)1,31}}=5.78, \quad p=0.023 ; \quad F_{(\mathrm{SR})}\right.$ $1,31=3.099, \quad p=0.088 ; \quad F_{(J Z L 195 \times \mathrm{SR}) 1,31}=2.20, \quad p=0.15$; Figure $4 \mathrm{~g}]$, and total frequency of play-related behaviors $\left[F_{(\mathrm{JZL} 195) 1,31}=7.09, \quad p=0.012 ; \quad F_{(\mathrm{SR}) 1,31}=2.87, \quad p=0.10\right.$; $F_{(\mathrm{JZL} 195 \times \mathrm{SR}) 1,31}=2.82, p=0.10$; Figure $\left.4 \mathrm{~h}\right]$. Post-hoc analysis revealed that the increase in the time $(p<0.05$; Figure $4 \mathrm{e})$ and frequency $(p<0.001$, Figure $4 f)$ of social interaction and in the time $(p<0.05$, Figure $4 \mathrm{~g})$ and frequency $(p<0.01$, Figure $4 \mathrm{~h})$ of play-related behaviors induced by JZL195 $(0.01 \mathrm{mg} / \mathrm{kg})$ was blocked by pre-treatment with a 

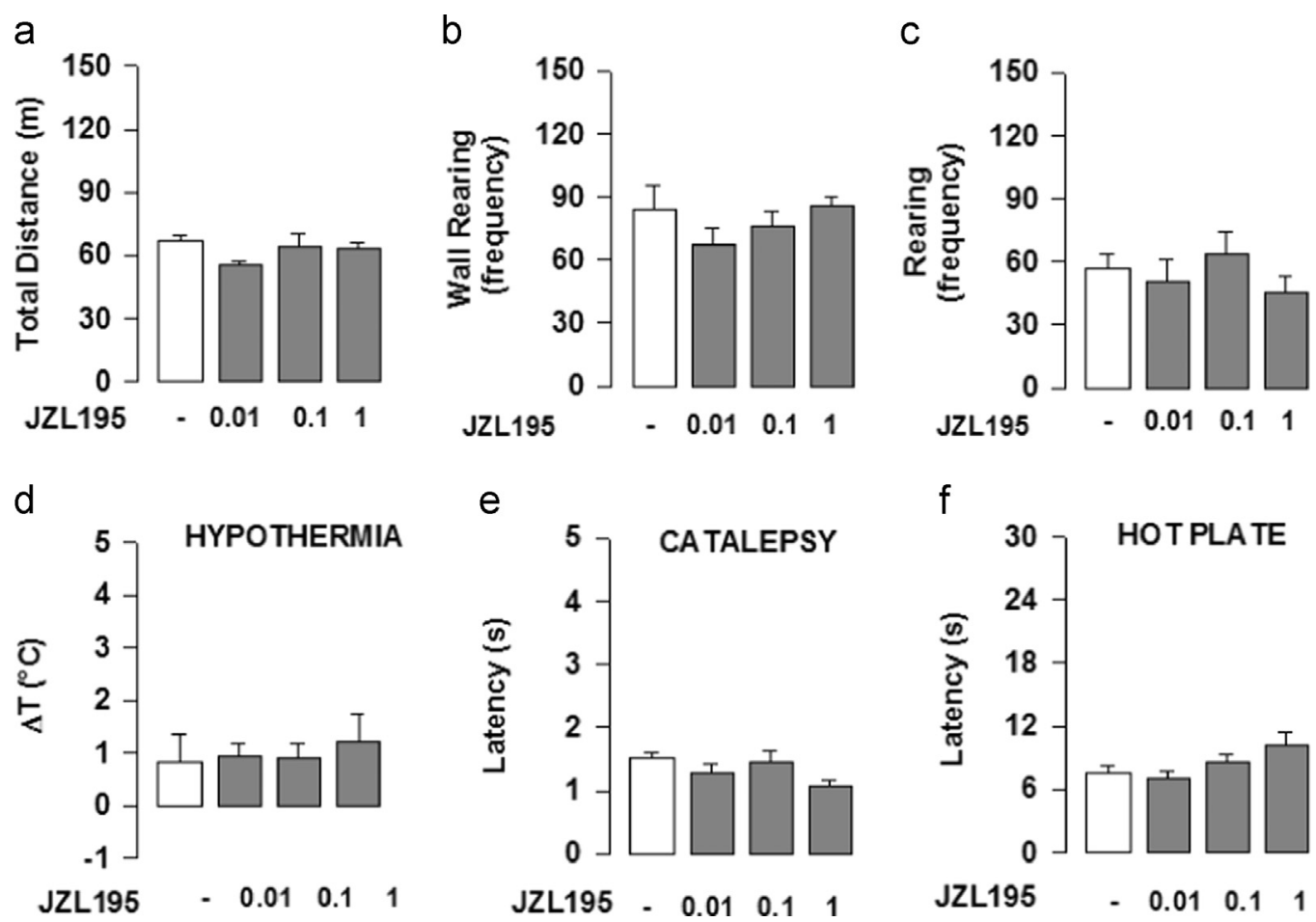

Figure 3 Effects of JZL195 in the tetrad assay for cannabimimetic activity in adolescent rats. JZL195 administration (0.01, 0.1 and $1 \mathrm{mg} / \mathrm{kg}$ ) did not affect locomotor activity (a), the frequency of wall rearing (b) and rearing (c) and it did not induce hypothermia (d), catalepsy (e) and antinociception ( $f$ ). Data represent mean \pm SEM total distance traveled (a), wall rearing (b) and rearing frequencies (c), body temperature (d), latency to move one or both forelimbs from the bar (e) and latency in licking the hind paws or jumping from the hot plate (f). $N=6-12$ per treatment group.

dose of SR141716A that had no effects by its own. Collectively, the results of this experiment show that JZL195, at the dose of $0.01 \mathrm{mg} / \mathrm{kg}$, increased social interaction in adult rats through activation of CB1 cannabinoid receptors.

\section{Effects of JZL195 on the elevated plus-maze test in adult rats}

A one way-ANOVA analysis performed on the parameters measured in the elevated plus-maze test gave the following results: percentage of time spent in the open arms $\left[F_{3,46}=5.27 ; p=0.003\right.$; Figure $\left.5 \mathrm{a}\right]$ and percentage of open arm entries $\left[F_{3,46}=5.61 ; p=0.0023\right.$; Figure 5b]. Post-hoc analysis showed that JZL195, at the dose of $1 \mathrm{mg} / \mathrm{kg}$, exerted anxiogenic-like effects in the elevated plus-maze test in adult rats, since it decreased the percentage of time spent in the open arms $(p<0.05$, Figure $5 a)$ and the percentage of open arm entries $(p<0.05$, Figure $5 \mathrm{~b})$. These effects were unrelated to changes in motor activity, since JZL195 did not affect the total number of closed arm entries $\left[F_{3,46}=2.15 ; p=0.11\right.$, data not shown $]$. To evaluate if the anxiogenic-like effects exerted by JZL195 were mediated by activation of CB1 cannabinoid receptors, we injected the CB1 cannabinoid receptor antagonist SR141716A before JZL195 $(1 \mathrm{mg} / \mathrm{kg})$. The two-way ANOVA analysis gave the following results: percentage of time spent in the open arms $\left[F_{(\mathrm{JZL195)1,40}}=8.58, \quad p=0.01 ; \quad F_{(\mathrm{SR}) 1,40}=1.99, \quad p=0.165 ;\right.$ $F_{(\mathrm{JZL} 195 \times \mathrm{SR}) 1,40}=4.33, p=0.04 ;$ Figure $\left.5 \mathrm{C}\right]$ and percentage of open arm entries [ $F_{(J Z L 195) 1,40}=0.27, p=0.61 ; F_{(S R)}$ $1,40=0.85, \quad p=0.36 ; \quad F_{(\mathrm{JZL} 195 \times \mathrm{SR}) 1,40}=9.01, \quad p=0.0046$;
Figure 5d]. Post-hoc analysis showed that the anxiogeniclike effects of JZL195 in the elevated plus-maze test were mediated by activation of CB1 cannabinoid receptors, since they were antagonized by the CB1 cannabinoid receptor antagonist SR141716A.

\section{Effects of JZL195 on brain AEA and 2-AG levels in adolescent and adult rats}

JZL195 induced specific dose- and age-dependent changes in brain AEA and 2-AG levels.

A two way-ANOVA for brain AEA (Figure 6a) and 2-AG (Figure 6b) levels in adolescent and adult rats treated with JZL195 gave the following results: AEA [ $F_{\text {(Treatment) }}$ $3,71=4.39, p<0.01 ; F_{(\text {Age }) 3,71}=0.85, p=0.36 ; F_{(\text {Treatment } x \text { - }}$ age) $3,71=51.24, \quad p<0.001 ;$ Figure $6 \mathrm{a}] ; 2$-AG $[F$ (Treatment)3,71 $=8.87$, $p<0.001 ; \quad F_{(\text {Age }) 3,71}=44.29, \quad p<0.001 ; \quad F_{(\text {Treatment } \times \text { age })}$ $3,71=3.28, p<0.05$; Figure $6 \mathrm{~b}]$. Post-hoc analysis revealed age-related changes in brain AEA but not 2-AG levels: thus, baseline AEA levels were higher in vehicle-treated adult compared to vehicle-treated adolescent rats $(p<0.001$, Figure 6a), while 2-AG levels were stable across ages (Figure 6b). In adolescent rats, JZL195 increased AEA levels at the dose of $1 \mathrm{mg} / \mathrm{kg}(p<0.01$, Figure $6 \mathrm{a})$, while it increased 2-AG levels at the doses of 0.01 and $1 \mathrm{mg} / \mathrm{kg}$ $(p<0.05$, Figure $6 \mathrm{~b})$. In adult rats, JZL195 did not affect brain AEA content at any dose tested (Figure 6a); conversely, all doses of JZL195 increased brain 2-AG levels $(p<0.05$, for $0.01 \mathrm{mg} / \mathrm{kg} ; \quad p<0.001$, for $0.1 \mathrm{mg} / \mathrm{kg}$; $p<0.01$, for $1 \mathrm{mg} / \mathrm{kg}$; Figure $6 \mathrm{~b})$. 
a

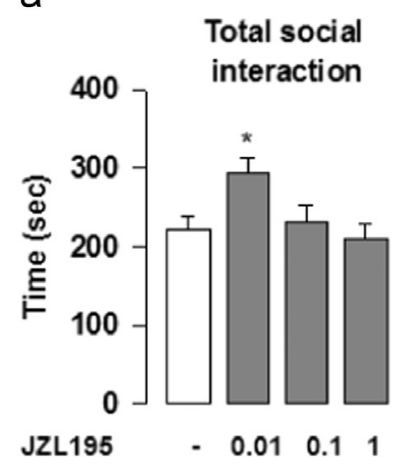

e

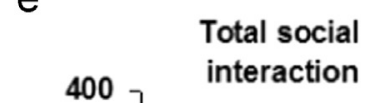

b

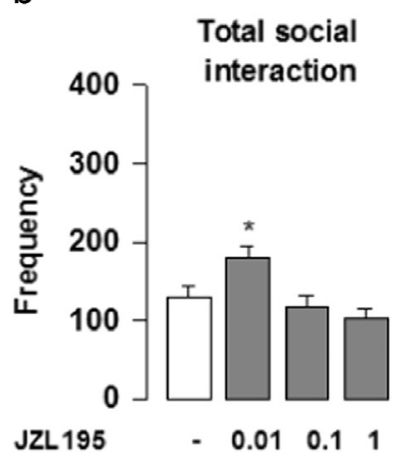

f

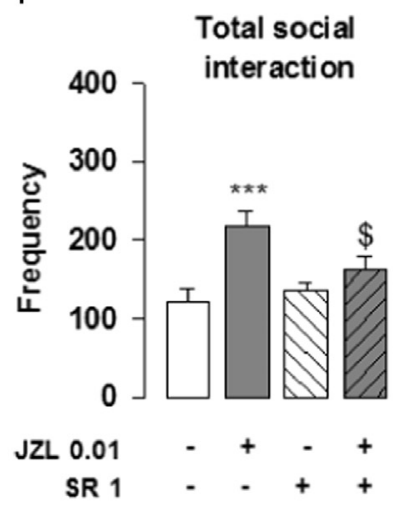

C

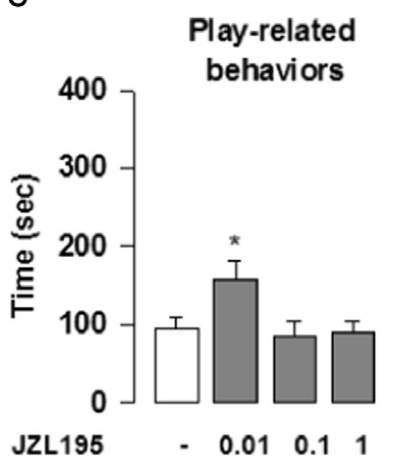

g

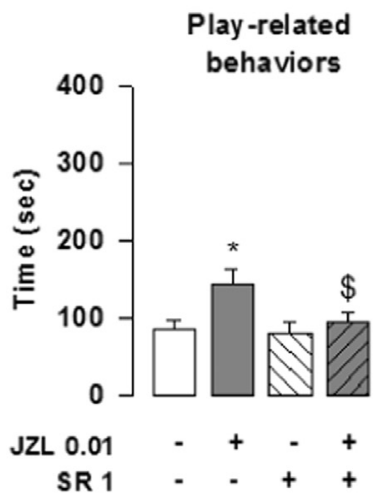

d

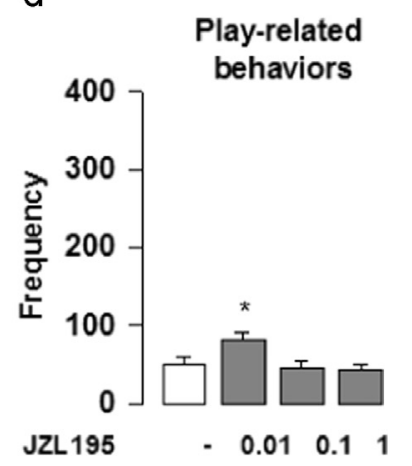

h

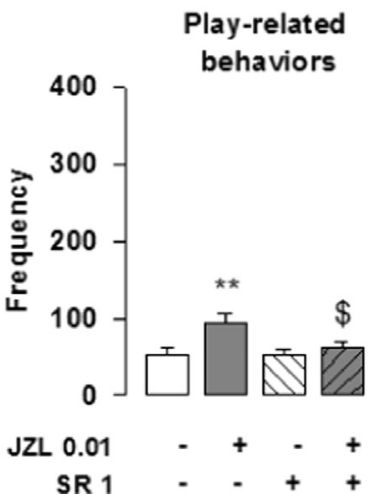

Figure 4 Effects of JZL195 on social interaction in adult rats. At the dose of $0.01 \mathrm{mg} / \mathrm{kg}$, JZL195 increased the total time (a) and frequency (b) of social interaction and the total time (c) and frequency (d) of play-related behaviors in adult rats. Pre-treatment with the CB1 cannabinoid receptor antagonist SR141716A (1 mg/kg; i.p.) antagonized these effects (e-h). Data represent mean \pm SEM time $(a, e)$ and frequency $(b, f)$ of total social interaction during 10-min session and mean \pm SEM time (c, g) and frequency $(\mathrm{d}, \mathrm{h})$ of play-related behaviors. ${ }^{*} p<0.05,{ }^{* *} p<0.01$ and ${ }^{* * *} p<0.001$ vs. vehicle treatment; ${ }^{\$} p<0.05$ vs. vehicle/JZL195 (Student-Newman-Keuls post-hoc test). $N=9-13$ per treatment group.

\section{Discussion}

Selective pharmacological inhibition of FAAH and MAGL, the enzymes that mainly catalyze the hydrolysis of the endocannabinoids AEA and 2-AG, respectively, provided a substantial support for a specific role of each of these lipid messengers in many physiological and behavioral processes, including motivation and emotions (Bari et al., 2006; Lutz, 2009; Petrosino and Di Marzo, 2010; Trezza and Vanderschuren, 2008a). Interestingly, in recent years a previously unsuspected interaction between these two endocannabinoids has been proven, thus leading to the hypothesis that they could have, depending on circumstances, different functional roles (Di Marzo and Cristino, 2008; Maccarrone et al., 2008).

To investigate the relative contribution and/or potential overlapping roles of $A E A$ and 2-AG signaling pathways in socio-emotional responses across development, we tested the effects of the dual FAAH/MAGL inhibitor JZL195, that induces a simultaneous elevation in both AEA and 2-AG local signaling (Long et al., 2009b), on social and anxiety-like behaviors in adolescent and adult rats.

We found that, at the dose of $0.01 \mathrm{mg} / \mathrm{kg}$, JZL195 increased the frequency of pinning and pouncing, the two most characteristic parameters of social play behavior in adolescent rats. These effects were mediated by activation of CB1 cannabinoid receptors, since they were antagonized by pre-treatment with the CB1 cannabinoid receptor antagonist SR141716A. This dose of JZL195 selectively increased play-related behaviors, since it did not alter general social exploration and did not affect behavior in the elevated plus-maze test. The effects of JZL195 on social behavior in adolescent rats were biphasic since the drug, administered at the dose of $1 \mathrm{mg} / \mathrm{kg}$, decreased the total time spent in general social exploration, without affecting play-related behaviors. At the dose of $1 \mathrm{mg} / \mathrm{kg}$, JZL195 also induced an anxiogenic-like profile in adolescent rats tested in the elevated plus-maze test. Both these effects were mediated by activation of CB1 cannabinoid receptors.

When JZL195 was administered to adult rats at the dose of $0.01 \mathrm{mg} / \mathrm{kg}$, it increased the total time and frequency of social behaviors, both related and unrelated to play, through the activation of CB1 cannabinoid receptors, with no effects in the elevated plus-maze. Conversely, at the dose of $1 \mathrm{mg} / \mathrm{kg}$, JZL195 did not affect adult social interaction, but induced CB1-dependent anxiogenic-like effects in the elevated plusmaze test.

It has been shown that JZL195 can induce in rodents effects similar to those induced by the main active component of Cannabis sativa, delta 9-tetrahydrocannabinol 
a
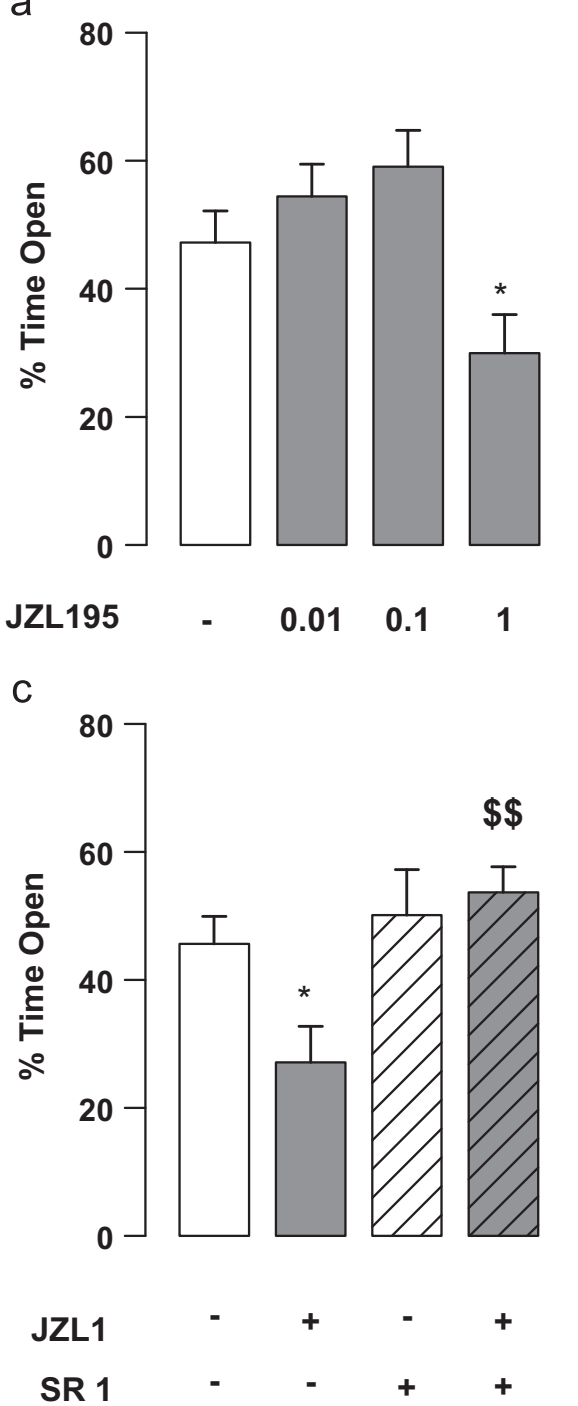

b

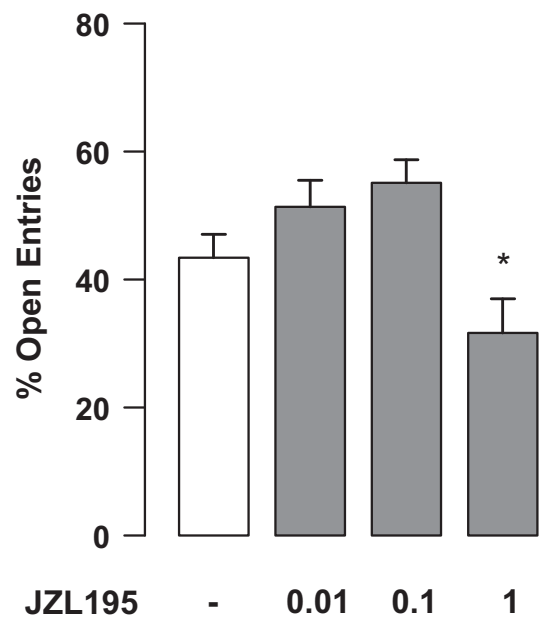

d

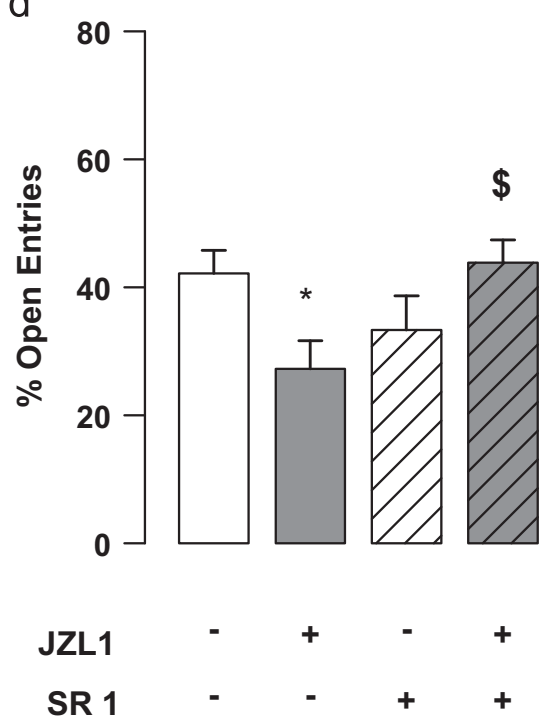

Figure 5 Effects of JZL195 in the elevated plus-maze test in adult rats. At the dose of $1 \mathrm{mg} / \mathrm{kg}$, JZL195 decreased the percentage of total time spent in the open arms (a) and the percentage of open arm entries (b) in the elevated plus-maze test in adult rats. Pretreatment with the CB1 cannabinoid receptor antagonist SR141716A (1 mg/kg; i.p.) antagonized these effects (c, d). Data represent mean \pm SEM percentage of total time spent in open arms $(a, c)$ and open arm entries (b, d). ${ }^{*} p<0.05$ vs. vehicle treatment; ${ }^{\$} p<0.05,{ }^{\$} p<0.01$ vs. vehicle/JZL195 (Student-Newman-Keuls posthoc test). $N=8-16$ per treatment group.

(THC). First, JZL195 impaired short-term spatial memory in the Morris water maze task in adult mice (Wise et al., 2012), suggesting that simultaneous increase in brain AEA and 2-AG levels results in disrupted memory performance. Second, unlike selective FAAH or MAGL inhibitors, JZL195 induced profound THC-like effects in a drug discrimination paradigm in mice (Long et al., 2009b). Third, it induced hypolocomotion in rats through the simultaneous increase in 2-AG and AEA levels in several brain regions (Seillier et al., 2014). To discriminate, if the effects induced by JZL195 were behaviorally specific or could be due to changes in locomotor activity or THC-like behavioral effects, we tested JZL195treated rats in the tetrad assay for cannabimimetic activity, consisting of tests for antinociception, catalepsy, hypomotility and hypothermia (Compton et al., 1992; Long et al., $2009 \mathrm{~b})$. The results of these experiments show that the effects of JZL195 on social and anxiety-like behaviors were behaviorally specific, since at the doses that affected behavior in the social interaction and elevated plus-maze tests, JZL195 did not induce changes in locomotion or other THC-like effects. Thus, while high doses of JZL195 have cannabimimetic activity, low doses induce specific effects on emotionality and sociability in rats.

To investigate the potential neurochemical mechanisms underlying the behavioral effects of JZL195, we measured brain AEA and 2-AG levels in adolescent and adult JZL195treated rats. First, we found age-dependent baseline changes in brain AEA but not 2-AG levels. Thus, brain AEA levels were higher in vehicle-treated adult compared to adolescent rats, while 2-AG levels were stable across the two ages. This is in line with previous findings reporting the occurrence of developmental increases in AEA but not 2-AG levels in the rat brain (Berrendero et al., 1999; Lee et al., 2013; Rubino et al., 2014). The observed increase in brain 
a
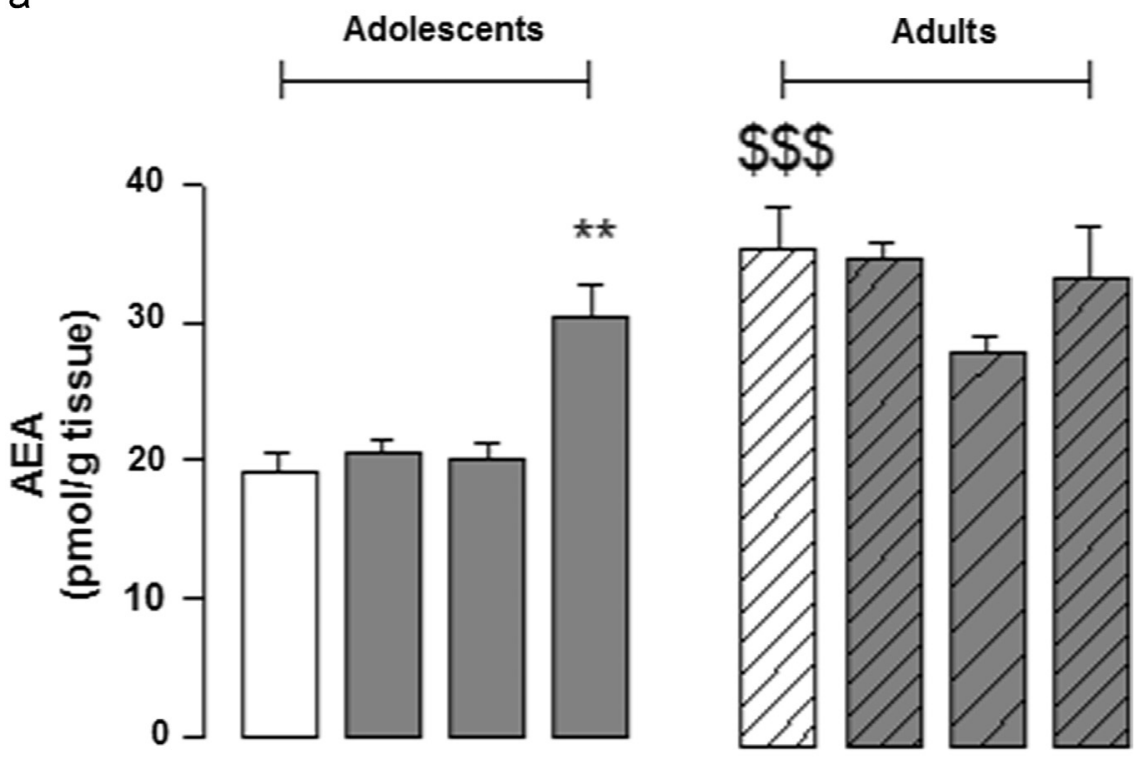

$$
\text { JZL195 }
$$

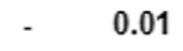

$\begin{array}{ll}0.1 & 1\end{array}$

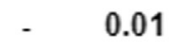

0.1

1

b

Adolescents
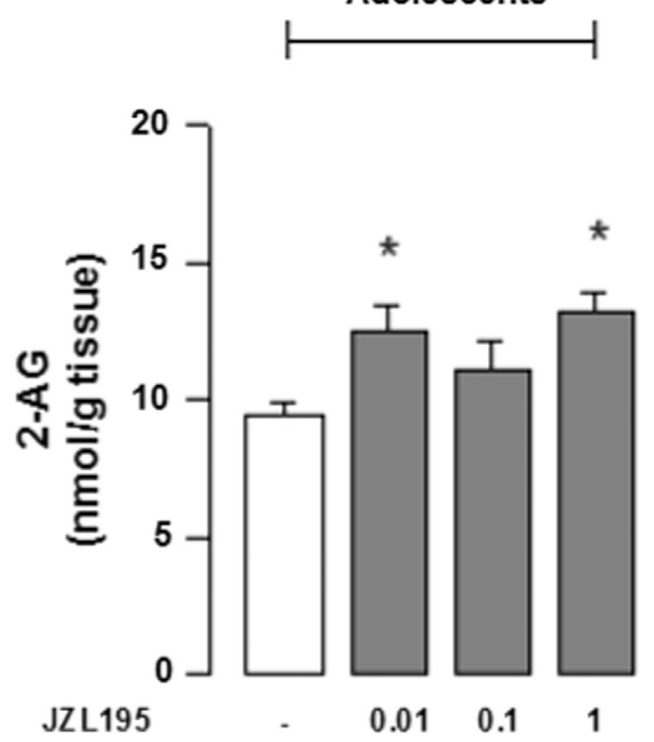

Adults
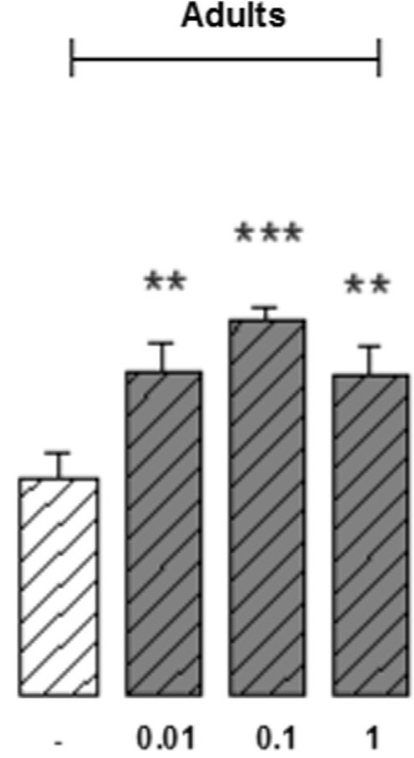

Figure 6 Effects of JZL195 on brain AEA and 2-AG levels in adolescent and adult rats. Baseline AEA levels were higher in vehicletreated adult rats compared to vehicle-treated adolescent rats (a). In adolescent rats, JZL195 increased brain AEA levels at the dose of $1 \mathrm{mg} / \mathrm{kg}(\mathrm{a})$, while it increased brain 2-AG levels (b) at the doses of 0.01 and $1 \mathrm{mg} / \mathrm{kg}$. In adult rats, JZL195 increased brain 2-AG levels at all doses tested (b), without any change in AEA content (a). Data represent mean \pm SEM AEA and 2-AG analyte levels. ${ }^{*} p<0.05,{ }^{* *} p<0.01 ;{ }^{* * *} p<0.001$ vs. vehicle treatment of the corresponding age group; ${ }^{\$ \$} \mathrm{p}<0.001$ vs. vehicle-treated adolescent rats (Student-Newman-Keuls post-hoc test). $N=9-10$ per treatment group.

AEA levels from adolescence to adulthood may depend on parallel developmental changes in the activity of either FAAH or AEA synthesizing enzymes. To support the first possibility, it has been shown that FAAH activity is higher in several brain regions of adolescent than adult rats (Lee et al., 2013; Rubino et al., 2014).

JZL195 induced specific dose- and age-dependent changes in brain AEA and 2-AG levels. At the dose of $0.01 \mathrm{mg} / \mathrm{kg}$, it increased 2-AG levels in the brain of adolescent rats without changing AEA content, suggesting that the play-enhancing effects induced by this dose of JZL195 in adolescent rats are mediated by brain 2-AG rather than AEA elevation. We have previously shown that URB597, that increases AEA activity by inhibiting its hydrolysis, also enhances social play behavior through activation of CB1 cannabinoid receptors (Trezza et al., 2012b; Trezza and Vanderschuren, 2008a). The present results extend our previous findings by providing the first evidence for a specific role of 2-AG in social play behavior in adolescent rats. The failure to correlate the increase in social play behavior induced by this dose of JZL195 with any change in 
brain AEA levels may be due either to the inability of this dose of JZL195 to significantly inhibit FAAH activity or to changes of AEA levels occurring in specific brain areas only. Indeed, our previous studies demonstrated that social play behavior increased AEA levels in the amygdala and nucleus accumbens but not prefrontal cortex and hippocampus of adolescent rats (Trezza et al., 2012b). Unlike our previous study, here we measured whole brain AEA and 2-AG levels in rats that were not tested for social interaction. Thus, we cannot exclude the possibility that AEA would increase selectively in some brain regions modulating social behavior rather than others. Last, it has been shown that 2-AG is approximately 200 -fold more abundant than AEA in the rodent brain (Stella et al., 1997; Sugiura et al., 1995); thus, at the dose of $0.01 \mathrm{mg} / \mathrm{kg}$, it is still possible that JZL195 increased both brain 2-AG and AEA levels, but the latter may be undetectable through whole brain endocannabinoid measurement.

Conversely, a simultaneous increase in brain AEA and 2AG content was observed when adolescent rats were treated with $1 \mathrm{mg} / \mathrm{kg}$ of JZL195. Thus, a crosstalk between these two endocannabinoid signaling pathways may be responsible of the anxiety-like behavior displayed in the elevated plus-maze by adolescent rats treated with this dose of JZL195. Furthermore, since this dose of JZL195 reduced general social interaction without affecting social play behavior, these findings support the idea that, in young mammals, social behaviors related and unrelated to play can be dissociated, both behaviorally and neurobiologically.

Interestingly, when administered to adult rats, JZL195 selectively increased brain 2-AG levels at all doses tested, without changing AEA content. The lower FAAH activity displayed by adult rats compared to adolescent animals (Lee et al., 2013; Rubino et al., 2014) could explain why JZL195 did not affect brain AEA levels at any dose. Furthermore, these results suggest that both the increased sociability displayed by adult rats treated with JZL195 at the dose of $0.01 \mathrm{mg} / \mathrm{kg}$ and the anxiogenic phenotype induced by the drug at the dose of $1 \mathrm{mg} / \mathrm{kg}$ may be due to increased brain 2-AG levels, pointing to an important role of this lipid messenger in the socioemotional behavior of adult rats. Previous studies have shown that the administration of the selective MAGL inhibitor JZL184 reduced anxiety-like behaviors in adult rodents (AlmeidaSantos et al., 2013; Kinsey et al., 2011; Sciolino et al., 2011). These findings seem to be in contrast with our results showing anxiogenic-like effects induced by JZL195 at the dose of $1 \mathrm{mg} / \mathrm{kg}$, which were paralleled by increased brain 2-AG content. Differences in the rodent species, route of administration and doses used may account for these discrepancies. Furthermore, although MAGL is the primary enzyme responsible for $85 \%$ of $2-A G$ catabolism, other enzymes such as ABHD6 and ABHD12 contribute to 2-AG degradation (Blankman et al., 2007). It has been reported that JZL195 inhibits ABHD6 but not any of the other brain serine hydrolases in mice (Long et al., 2009b). Thus, it is possible that inhibition of this minor 2-AG catabolic enzyme by JZL195 may have consequences on anxiety-related behaviors that differ from those induced by selective MAGL inhibition. This possibility deserves further investigation.

To summarize, our results show that AEA and 2-AG signaling pathways engage in extensive interactions in the rodent brain to modulate socio-emotional behavior and that the dual FAAH/MAGL inhibitor JZL195 serves as a useful pharmacological probe to evaluate the behavioral impact of simultaneous elevations in AEA and 2-AG endogenous levels. Furthermore, these findings open a promising role for 2-AG in the modulation of social behavior in both adolescent and adult rats, which until now was mainly attributable to AEA (Marco et al., 2011; Trezza et al., 2012b). However, whether these interactions occur via crosstalk between distinct AEAand 2-AG-regulated neuronal circuits or through co-signaling at the same CB1 cannabinoid receptors remains unknown and warrant further investigation.

\section{Role of funding sources}

Supported by Veni Grant 91611052 (Nederlandse Organisatie voor Wetenschappelijk Onderzoek, V.T.), Marie Curie Career Reintegration Grant PCIG09-GA-2011-293589 (Seventh Framework Programme People, V.T.), Futuro in Ricerca 2010 Grant RBFR10XKHS (Italian Ministry for University and Scientific Research, V.T., P.C.), Human Frontiers Science Program Young Investigator Grant RGY0077 (P.C.) and Natural Sciences and Engineering Research Council of Canada Grant 436225-2013 (NSERC, M.N.H.). These funding agencies had no further role in study design, in the collection, analysis and interpretation of data, in the writing of the report and in the decision to submit the paper for publication.

The authors declare no competing financial interests in relation to the work described.

\section{Contributors}

All authors contributed to and have approved the final manuscript. Antonia Manduca, Maria Morena and Michela Servadio performed the experiments. Antonia Manduca wrote the first draft of the manuscript. Patrizia Campolongo, Maura Palmery, Luigia Trabace, Louk J.M.J. Vanderschuren, Matthew N. Hill and Vincenzo Cuomo analyzed and contributed to the design of the experiments and edited the manuscript. Viviana Trezza supervised the project, designed the experiments and wrote the manuscript.

\section{Conflicts of interest}

All authors declare no potential conflicts of interest in relation to the work described.

On behalf of all-co-authors,

Viviana Trezza.

\section{Acknowledgments}

We thank Lidia Montebello, Riccardo Dore and Valentina De Castro (Master students, Department of Physiology and Pharmacology, Sapienza, University of Rome) for their technical help. We would also like to acknowledge the Southern Alberta Mass Spectrometry (SAMS) Centre (www.sams.ucalgary.ca), located in and supported by the Cumming School of Medicine, University of Calgary for their services in targeted LC-MS-MS.

\section{References}

Almeida-Santos, A.F., Gobira, P.H., Rosa, L.C., Guimaraes, F.S., Moreira, F.A., Aguiar, D.C., 2013. Modulation of anxiety-like behavior by the endocannabinoid 2-arachidonoylglycerol (2-AG) in the dorsolateral periaqueductal gray. Behav. Brain Res. 252, 10-17. 
Bari, M., Battista, N., Fezza, F., Gasperi, V., Maccarrone, M., 2006. New insights into endocannabinoid degradation and its therapeutic potential. Mini Rev. Med. Chem. 6, 257-268.

Berrendero, F., Sepe, N., Ramos, J.A., Di Marzo, V., Fernandez-Ruiz, J.J., 1999. Analysis of cannabinoid receptor binding and mRNA expression and endogenous cannabinoid contents in the developing rat brain during late gestation and early postnatal period. Synapse 33, 181-191.

Blankman, J.L., Simon, G.M., Cravatt, B.F., 2007. A comprehensive profile of brain enzymes that hydrolyze the endocannabinoid 2arachidonoylglycerol. Chem. Biol. 14, 1347-1356.

Campolongo, P., Trezza, V., Ratano, P., Palmery, M., Cuomo, V., 2011. Developmental consequences of perinatal cannabis exposure: behavioral and neuroendocrine effects in adult rodents. Psychopharmacology 214, 5-15.

Chang, J.W., Niphakis, M.J., Lum, K.M., Cognetta 3rd, A.B., Wang, C., Matthews, M.L., Niessen, S., Buczynski, M.W., Parsons, L.H., Cravatt, B.F., 2012. Highly selective inhibitors of monoacylglycerol lipase bearing a reactive group that is bioisosteric with endocannabinoid substrates. Chem. Biol. 19, 579-588.

Compton, D.R., Gold, L.H., Ward, S.J., Balster, R.L., Martin, B.R., 1992. Aminoalkylindole analogs: cannabimimetic activity of a class of compounds structurally distinct from delta 9tetrahydrocannabinol. J. Pharmacol. Exp. Ther. 263, 1118-1126.

Di Marzo, V., Cristino, L., 2008. Why endocannabinoids are not all alike. Nat. Neurosci. 11, 124-126.

Forman, L.J., 2003. The effect of cannabinoid receptor antagonism with SR141716A on antinociception induced by cocaine and the NMDA receptor antagonist, MK-801. Brain Res. Bull. 61, 153-158.

Gobbi, G., Bambico, F.R., Mangieri, R., Bortolato, M., Campolongo, P., Solinas, M., Cassano, T., Morgese, M.G., Debonnel, G., Duranti, A., Tontini, A., Tarzia, G., Mor, M., Trezza, V., Goldberg, S.R., Cuomo, V., Piomelli, D., 2005. Antidepressant-like activity and modulation of brain monoaminergic transmission by blockade of anandamide hydrolysis. Proc. Natl. Acad. Sci. U. S. A. 102, 18620-18625.

Hill, M.N., Karacabeyli, E.S., Gorzalka, B.B., 2007. Estrogen recruits the endocannabinoid system to modulate emotionality. Psychoneuroendocrinology 32, 350-357.

Jung, K.M., Sepers, M., Henstridge, C.M., Lassalle, O., Neuhofer, D., Martin, H., Ginger, M., Frick, A., DiPatrizio, N.V., Mackie, K., Katona, I., Piomelli, D., Manzoni, O.J., 2012. Uncoupling of the endocannabinoid signalling complex in a mouse model of fragile X syndrome. Nat. Commun. 3, 1080.

Kathuria, S., Gaetani, S., Fegley, D., Valino, F., Duranti, A., Tontini, A., Mor, M., Tarzia, G., La Rana, G., Calignano, A., Giustino, A., Tattoli, M., Palmery, M., Cuomo, V., Piomelli, D., 2003. Modulation of anxiety through blockade of anandamide hydrolysis. Nat. Med. 9, 76-81.

Kinsey, S.G., O’Neal, S.T., Long, J.Z., Cravatt, B.F., Lichtman, A.H., 2011. Inhibition of endocannabinoid catabolic enzymes elicits anxiolytic-like effects in the marble burying assay. Pharmacol. Biochem. Behav. 98, 21-27.

Lee, T.T., Hill, M.N., Hillard, C.J., Gorzalka, B.B., 2013. Temporal changes in $\mathrm{N}$-acylethanolamine content and metabolism throughout the peri-adolescent period. Synapse 67, 4-10.

Long, J.Z., Li, W., Booker, L., Burston, J.J., Kinsey, S.G., Schlosburg, J.E., Pavon, F.J., Serrano, A.M., Selley, D.E., Parsons, L. H., Lichtman, A.H., Cravatt, B.F., 2009a. Selective blockade of 2-arachidonoylglycerol hydrolysis produces cannabinoid behavioral effects. Nat. Chem. Biol. 5, 37-44.

Long, J.Z., Nomura, D.K., Vann, R.E., Walentiny, D.M., Booker, L., Jin, X., Burston, J.J., Sim-Selley, L.J., Lichtman, A.H., Wiley, J.L., Cravatt, B.F., 2009b. Dual blockade of FAAH and MAGL identifies behavioral processes regulated by endocannabinoid crosstalk in vivo. Proc. Natl. Acad. Sci. U. S. A. 106, 20270-20275.
Lutz, B., 2009. Endocannabinoid signals in the control of emotion. Curr. Opin. Pharmacol. 9, 46-52.

Maccarrone, M., Rossi, S., Bari, M., De Chiara, V., Fezza, F., Musella, A., Gasperi, V., Prosperetti, C., Bernardi, G., Finazzi-Agro, A. Cravatt, B.F., Centonze, D., 2008. Anandamide inhibits metabolism and physiological actions of 2-arachidonoylglycerol in the striatum. Nat. Neurosci. 11, 152-159.

Manduca, A., Servadio, M., Campolongo, P., Palmery, M., Trabace, L., Vanderschuren, L.J., Cuomo, V., Trezza, V., 2014. Strain- and context-dependent effects of the anandamide hydrolysis inhibitor URB597 on social behavior in rats. Eur. Neuropsychopharmacol. 24, 1337-1348.

Marco, E.M., Laviola, G., 2011. The endocannabinoid system in the regulation of emotions throughout lifespan: a discussion on therapeutic perspectives. J. Psychopharmacol. 26, 150-163.

Marco, E.M., Rapino, C., Caprioli, A., Borsini, F., Maccarrone, M., Laviola, G., 2011. Social encounter with a novel partner in adolescent rats: activation of the central endocannabinoid system. Behav. Brain Res. 220, 140-145.

Mechoulam, R., Hanus, L.O., Pertwee, R., Howlett, A.C., 2014. Early phytocannabinoid chemistry to endocannabinoids and beyond. Nat. Rev. Neurosci. 15, 757-764.

Morena, M., Campolongo, P., 2014. The endocannabinoid system: an emotional buffer in the modulation of memory function. Neurobiol. Learn. Mem. 112, 30-43.

Naidu, P.S., Varvel, S.A., Ahn, K., Cravatt, B.F., Martin, B.R., Lichtman, A.H., 2007. Evaluation of fatty acid amide hydrolase inhibition in murine models of emotionality. Psychopharmacology 192, 61-70.

Niesink, R.J., Van Ree, J.M., 1989. Involvement of opioid and dopaminergic systems in isolation-induced pinning and social grooming of young rats. Neuropharmacology 28, 411-418.

Niphakis, M.J., Cognetta 3rd, A.B., Chang, J.W., Buczynski, M.W., Parsons, L.H., Byrne, F., Burston, J.J., Chapman, V., Cravatt, B. F., 2013. Evaluation of NHS carbamates as a potent and selective class of endocannabinoid hydrolase inhibitors. ACS Chem. Neurosci. 4, 1322-1332.

Pellis, S.M., Pellis, V.C., 1987. Play-fighting differs from serious fighting in both target of attack and tactics of fighting in the laboratory rat Rattus norvegicus. Aggress. Behav. 13, 227-242.

Pellow, S., File, S.E., 1986. Anxiolytic and anxiogenic drug effects on exploratory activity in an elevated plus-maze: a novel test of anxiety in the rat. Pharmacol. Biochem. Behav. 24, 525-529.

Petrosino, S., Di Marzo, V., 2010. FAAH and MAGL inhibitors: therapeutic opportunities from regulating endocannabinoid levels. Curr. Opin. Investig. Drugs 11, 51-62.

Piomelli, D., 2003. The molecular logic of endocannabinoid signalling. Nat. Rev. Neurosci. 4, 873-884.

Rademacher, D.J., Hillard, C.J., 2007. Interactions between endocannabinoids and stress-induced decreased sensitivity to natural reward. Prog. Neuropsychopharmacol. Biol. Psychiatry 31, 633-641.

Realini, N., Vigano, D., Guidali, C., Zamberletti, E., Rubino, T., Parolaro, D., 2011. Chronic URB597 treatment at adulthood reverted most depressive-like symptoms induced by adolescent exposure to THC in female rats. Neuropharmacology 60 , 235-243.

Rubino, T., Prini, P., Piscitelli, F., Zamberletti, E., Trusel, M., Melis, M., Sagheddu, C., Ligresti, A., Tonini, R., Di Marzo, V., Parolaro, D., 2014. Adolescent exposure to THC in female rats disrupts developmental changes in the prefrontal cortex. Neurobiol. Dis. 73C, 60-69.

Sciolino, N.R., Zhou, W., Hohmann, A.G., 2011. Enhancement of endocannabinoid signaling with JZL184, an inhibitor of the 2 arachidonoylglycerol hydrolyzing enzyme monoacylglycerol lipase, produces anxiolytic effects under conditions of high environmental aversiveness in rats. Pharmacol. Res. 64, 226-234. 
Segatto, M., Manduca, A., Lecis, C., Rosso, P., Jozwiak, A., Swiezewska, E., Moreno, S., Trezza, V., Pallottini, V., 2014. Simvastatin treatment highlights a new role for the isoprenoid/ cholesterol biosynthetic pathway in the modulation of emotional reactivity and cognitive performance in rats. Neuropsychopharmacology 39, 841-854.

Seillier, A., Dominguez Aguilar, D., Giuffrida, A., 2014. The dual FAAH/MAGL inhibitor JZL195 has enhanced effects on endocannabinoid transmission and motor behavior in rats as compared to those of the MAGL inhibitor JZL184. Pharmacol. Biochem. Behav. 124, 153-159.

Stella, N., Schweitzer, P., Piomelli, D., 1997. A second endogenous cannabinoid that modulates long-term potentiation. Nature 388, 773-778.

Sugiura, T., Kondo, S., Sukagawa, A., Nakane, S., Shinoda, A., Itoh, K., Yamashita, A., Waku, K., 1995. 2-Arachidonoylglycerol: a possible endogenous cannabinoid receptor ligand in brain. Biochem. Biophys. Res. Commun. 215, 89-97.

Trezza, V., Baarendse, P.J., Vanderschuren, L.J., 2009. Prosocial effects of nicotine and ethanol in adolescent rats through partially dissociable neurobehavioral mechanisms. Neuropsychopharmacology 34, 2560-2573.

Trezza, V., Campolongo, P., Manduca, A., Morena, M., Palmery, M., Vanderschuren, L.J., Cuomo, V., 2012a. Altering endocannabinoid neurotransmission at critical developmental ages: impact on rodent emotionality and cognitive performance. Front. Behav. Neurosci. 6, 2.
Trezza, V., Damsteegt, R., Manduca, A., Petrosino, S., Van Kerkhof, L.W., Pasterkamp, R.J., Zhou, Y., Campolongo, P., Cuomo, V., Di Marzo, V., Vanderschuren, L.J., 2012b. Endocannabinoids in amygdala and nucleus accumbens mediate social play reward in adolescent rats. J. Neurosci. 32, 14899-14908.

Trezza, V., Vanderschuren, L.J., 2008a. Bidirectional cannabinoid modulation of social behavior in adolescent rats. Psychopharmacology 197, 217-227.

Trezza, V., Vanderschuren, L.J., 2008b. Cannabinoid and opioid modulation of social play behavior in adolescent rats: differential behavioral mechanisms. Eur. Neuropsychopharmacol. 18, 519-530.

Trezza, V., Vanderschuren, L.J., 2009. Divergent effects of anandamide transporter inhibitors with different target selectivity on social play behavior in adolescent rats. J. Pharmacol. Exp. Ther. 328, 343-350.

Vanderschuren, L.J., Trezza, V., Griffioen-Roose, S., Schiepers, O.J., Van Leeuwen, N., De Vries, T.J., Schoffelmeer, A.N., 2008. Methylphenidate disrupts social play behavior in adolescent rats. Neuropsychopharmacology 33, 2946-2956.

Wise, L.E., Long, K.A., Abdullah, R.A., Long, J.Z., Cravatt, B.F., Lichtman, A.H., 2012. Dual fatty acid amide hydrolase and monoacylglycerol lipase blockade produces THC-like Morris water maze deficits in mice. ACS Chem. Neurosci. 3, 369-378.

Wotjak, C.T., 2005. Role of endogenous cannabinoids in cognition and emotionality. Mini Rev. Med. Chem. 5, 659-670. 